\title{
The Molecular Detection of Human Bocavirus (HBoV) in Colorectal Tissue with Malignant and Non-Malignant Lesions
}

\author{
Mohammad Hadi Karbalaie Niya ${ }^{1}$, Hossein Ajdarkosh ${ }^{2 *}$, Fahimeh Safarnezhad \\ Tameshkel' ${ }^{2}$, Mahshid Panahi², Maryam Tabasi ${ }^{3}$, Behnaz Bouzari ${ }^{4}$, Mahdi \\ Alemrajabi $^{5}$, Hossein Keyvani ${ }^{2}$
}

\begin{abstract}
Background: Colorectal cancer (CRC) as a worldwide human health concern is identified being a multifactorial subject that infection with specific viral particles such as oncogenic viruses is research interest. Human bocavirus (HBoV) as a recent isolated virus has been investigated in many respiratory and enteric diseases but rare studies evaluates it in tissue specimens especially in cancerous sections. The aim of this study was to detect the presence of HBoV genome and its genotyping in CRC patient's tissue and compare the result with matched healthy control group tissue. Method: in this retrospective case-control study, CRC cases were sporadic and non-familial cancerous while control subjects had healthy or non-malignant lesions in colon tissue. A conventional-PCR performed by specific primers for HBoV VP1 gene. After sequencing of positive PCR products, raw data used for trimming and alignment by bioinformatics software CLC Main Workbench 5 and MEGA5. SPSS v.22 used for statistical calculations. Result: a total of 157 subjects were participated that 66 were diagnosed as CRC cases and 91 were non-CRC colon tissue as control group that matched by the cases. The mean age $(\mathrm{y}) \pm$ standard deviation of each case and control groups were $59.35 \pm 14.48$ and 57.21 \pm 14.66 , respectively. PCR results showed there were $1.3 \%(2 / 157) \mathrm{HBoV}$ positive (of each groups one was positive). Sequencing analysis showed all were HBoV-1 genotype. Conclusion: our study showed there are low rate of HBoV genome in Iranian CRC and non-CRC colon tissue. Furthermore, the predominant genotype in our studied subsets were HBoV-1 according to phylogenetic analysis.
\end{abstract}

Keywords: Colorectal cancer (CRC)- human bocavirus (HBoV)- phylogenetic analysis- Viral infection

Asian Pac J Cancer Prev, 19 (11), 3295-3299

\section{Introduction}

Colorectal cancer (CRC) is the third most common cancer worldwide that the higher incidence rates seems in developing countries (Karbalaie Niya et al., 2016; koochak et al., 2016). Although, CRC slightly increasing in some specific developed European countries and decreased in USA, still it seems increasing in some eastern Europe, several Asian and south American countries (Siegel et al., 2017). CRC as a multifactorial disease has been investigated for its association with different individual, environmental, genetical factors as well as extrinsic infections (Siegel et al., 2017). Viral infections such as human papillomaviruses (HPVs), human herpes viruses, and human polyomaviruses association with CRC are intensively studied (Chen et al., 2015; Coelho et al., 2010; Munoz, 2000).

Oncogenic viruses such as Epstein-Barr virus (EBV), hepatitis $\mathrm{C}$ virus (HCV), hepatitis B virus (HBV), HPV, human herpes virus 8 (HHV8) and human T-lymphotropic virus type 1 (HTLV-I) are interesting topics in human cancer investigations that they could be a major cause of different malignancies (Afshar et al., 2018; Karbalaie Niya et al., 2018; Karbalaie Niya et al., 2017b; Keyvani et al., 2017).

Recently discovered Human bocavirus (HBoV), a single-stranded DNA virus, has been reported in respiratory and gastrointestinal diseases. Human bocavirus is a member of Bocaparvovirus genus, Parvovirinae subfamily, Parvoviridae family that identified by four genotypes (HBoV1-4). Since HBoV spreads worldwide, it reported from different complications such as respiratory tract infection (Allander et al., 2005), acute lymphoblastic leukemia (Koskenvuo et al., 2008), gastroenteritis, heart disorders (Brebion et al., 2014), encephalitis (Mitui et al., 2012) and in healthy blood

${ }^{I}$ Institute of Immunology and Infectious Diseases, ${ }^{2}$ Gastrointestinal and Liver Diseases Research Center, ${ }^{4}$ Department of Pathology and Laboratory Medicine, ${ }^{5}$ Firoozgar Clinical Research Development Center (FCRDC), Iran University of Medical Sciences, Tehran, ${ }^{3}$ Department of Virology, Faculty of Medicine, Ahvaz Jundishapur University of Medical Sciences, Ahvaz Iran. *For Correspondence: ajdarkosh1345@yahoo.com 
donors (Bonvicini et al., 2011). But there were rare studies to report $\mathrm{HBoV}$ in $\mathrm{CRC}$ patients specially in tissue samples (Li et al., 2012; Schildgen et al., 2013). HBoV-1 genotype was reported from both respiratory (Allander et al., 2005) and enteric infections (Romani et al., 2013) while $\mathrm{HBoV}-2,3$ and 4 were detected in enteric infections (Kapoor et al., 2010; Kapoor et al., 2009). Literatures suggest that $\mathrm{HBoV}$ has potential to associate with $\mathrm{CRC}$ complication since its four genotypes are commonly detected in enteric tract (Abdel-Moneim et al., 2016a).

In this regards, as a preliminary study in Iran, we aimed to detect the frequency of $\mathrm{HBoV}$ genome infection in $\mathrm{CRC}$ and non-CRC colonic tissue and introduce the predominant genotype by phylogenetic analysis.

\section{Materials and Methods}

\section{Ethical approval}

The present retrospective case-control study Ethics was approved by the Ethics Committee of Iran University of Medical Sciences, Tehran, Iran by the number IR.IUMS. REC 1395.26671. From the all of participants written consent was obtained.

\section{Subjects}

One hundred fifty seven individuals underwent total endoscopy and colonoscopy by Fujinon machine (Fujinon, Japan) that referred to hospitals affiliated to Iran University of Medical Sciences, Tehran, Iran from 2011 to 2016. Included CRC cases were being sporadic and non-familial cancerous and control subjects had not any malignant lesions that matched by age, sex and lesion location with cases. Excluded participants did not meet the inclusion criteria.

\section{Histopathology}

Of each patients archived formalin-fixed paraffinembedded (FFPE) blocks that reviewed by expert pathologist collected for DNA extraction. Data collected from the medical record repository. Hematoxylin and Eosin (H\&E) stained slides reviewed for enhance the accuracy of lesion selection. WHO grading system was used for tumor location, tumor histopathology, lymph node involvement and evidence of metastasis.

\section{Nucleic acid extraction}

Vibrating microtome (Leica VT 1000S, Leica Microsystems) was used for 20 micron dissections of each participants blocks. QIAamp ${ }^{\circledR}$ DNA FFPE Tissue Kit (QIAGEN, Hilden, Germany) performed for DNA extraction, according protocol (Basi et al., 2018; Eftekhaar et al., 2017; Karbalaie Niya et al., 2017a). NanoDrop ND-1000® (Thermo Fisher Scientific Inc., Waltham, MA, USA) spectrophotometry evaluates our isolated products purity. Extracted DNA was kept at- $20^{\circ} \mathrm{c}$ until further use.

\section{HBoV detection}

A conventional PCR performed for detection of HBoV DNA amplification. A pair of specific primers for HBoV VP1 gene were from previous study of Shen et al (Shen et al., 2013). The sequence of forward primer and reverse primer by the product size $579 \mathrm{bp}$ was same as previous study (Shen et al., 2013). The master mix prepared using template DNA or controls at a final concentration of 0.2-0.5 $\mu \mathrm{M}$, dNTP mix (Fermentas GmbH, Germany) corresponds to $0.5 \mathrm{mM}$, each primers correspond to 0.5 $\mu \mathrm{M}, \mathrm{MgCl}_{2}$ (Fermentas GmbH, Germany) corresponds to $1.5 \mu \mathrm{M}$, Taq DNA polymerase (Fermentas $\mathrm{GmbH}$, Germany) corresponds to 5 units/ $\mu 1$ and distilled water added to the rest of total $25 \mu \mathrm{l}$ volume. The PCR assay was performed by the Bio-Rad thermocycler (T100 ${ }^{\mathrm{TM}}$ Thermal Cycler) by the following heating program: $5 \mathrm{~min}$ at $95^{\circ} \mathrm{C}$; 45 cycles of the $30 \mathrm{~s}$ at $95^{\circ} \mathrm{C}, 30 \mathrm{~s}$ at $58^{\circ} \mathrm{C}$, and 40 s at $72^{\circ} \mathrm{C}$; and one final extension step $5 \mathrm{~min}$ at $72^{\circ} \mathrm{C}$. Visualization of PCR products performed by gel electrophoresis of $1.5 \%$ Agarose into the Tris-Borat-EDTA 1× (TBE 1×) buffer. Ethidium bromide staining used for visualization by UV transilluminator.

\section{Direct sequencing}

The High Pure PCR Product Purification Kit (Roche Diagnostic GmbH, Mannheim, Germany) was used for isolation of PCR products according to manufacturer's protocol. The ABI 3,730 XL sequencer (ABI, Foster City, California) was used for bidirectional sequencing using appropriate amount of primers. CLC Main Workbench 5 (CLC Bio, Aarhus, Denmark) and MEGA5 (www.megasoftware.net) Bioinformatics software were utilized for trimming the raw data, alignment of consensus sequences and phylogenetic tree drawing.

\section{Statistics}

Statistical analysis carried out by SPSS software version 22 (SPSS Inc., Chicago, IL, USA). The descriptive variables and frequencies calculated by $t$ test, chi-square test and or fisher exact test. The significant $\mathrm{p}$-value presumed the values less than 0.05 .

\section{Results}

\section{Participants}

From a total of 175 eligible individuals, based on availability and inclusion criteria, 157 were met the inclusion criteria and participated in the current study. Of them 66 were CRC cases and 91 were non-CRC controls by the mean age $(\mathrm{y}) \pm$ standard deviation of $59.35 \pm 14.48$ and $57.21 \pm 14.66$, respectively, that $57.6 \%$ of cases and $57.1 \%$ of controls were male (Table 1).

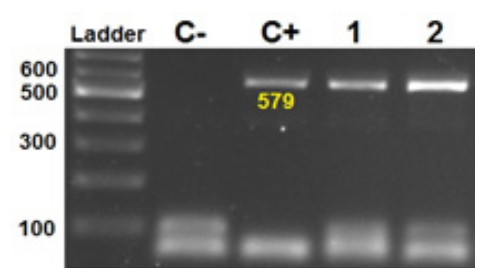

Figure 1. The $579 \mathrm{bp} \mathrm{Band} \mathrm{of} \mathrm{HBoV} \mathrm{Positive} \mathrm{PCR} \mathrm{in} \mathrm{our}$ Present Study Population $(\mathrm{n}=2)$. C-, non-template control (NTC); $\mathrm{C}+$, positive control (it was from previous study HBoV positive (Mortazavi et al., 2015)); 1 and 2 were positive isolates. 
Table 1. Demographic and Pathologic Features of Present Study Subjects ( $\mathrm{n}=157)$

\begin{tabular}{|c|c|c|c|c|c|c|c|}
\hline \multirow[t]{2}{*}{ Category of variables } & \multirow[t]{2}{*}{ Variables } & \multicolumn{2}{|c|}{ Male (\%) } & \multicolumn{2}{|c|}{ Female (\%) } & \multicolumn{2}{|c|}{ Total $(\%)$} \\
\hline & & Case & Control & Case & Control & Case & Control \\
\hline \multirow[t]{5}{*}{ Descriptive } & No. & $38(57.6)$ & $52(57.1)$ & $28(42.4)$ & $39(42.9)$ & $66(100)$ & $91(100)$ \\
\hline & Mean age & 59.13 & 56.50 & 59.64 & 58.15 & 59.35 & 57.21 \\
\hline & Std. Deviation & 14.601 & 15.624 & 14.589 & 13.412 & 14.486 & 14.661 \\
\hline & Std. Error & 2.369 & 2.167 & 2.757 & 2.148 & 1.783 & 1.537 \\
\hline & Range & $27-81$ & $15-89$ & $28-85$ & $26-81$ & $27-85$ & $15-89$ \\
\hline \multirow[t]{5}{*}{ Sample location } & Colon & $15(39.5)$ & $15(28.8)$ & $14(50.0)$ & $14(35.9)$ & $29(43.9)$ & $29(31.9)$ \\
\hline & Rectum & $10(26.3)$ & $16(30.8)$ & $3(10.7)$ & $9(23.1)$ & $13(19.7)$ & $25(27.5)$ \\
\hline & Cecum & $7(18.4)$ & $5(9.6)$ & $4(14.3)$ & $11(28.2)$ & $11(16.7)$ & $16(17.6)$ \\
\hline & Ileum & $1(2.6)$ & $4(7.7)$ & $1(3.6)$ & $1(2.6)$ & $2(3.0)$ & $5(5.5)$ \\
\hline & Sigmoid & $5(13.2)$ & $12(23.1)$ & $6(21.4)$ & $4(10.3)$ & $11(16.7)$ & $16(17.6)$ \\
\hline \multirow[t]{4}{*}{ Differentiation } & Well & $21(55.3)$ & - & $15(55.6)$ & - & $36(55.4)$ & - \\
\hline & Moderate & $13(34.2)$ & - & $8(29.6)$ & - & $21(32.3)$ & - \\
\hline & Poorly & $1(2.6)$ & - & - & - & $1(1.5)$ & - \\
\hline & Undifferentiated & $3(7.9)$ & - & $4(14.8)$ & - & $7(10.8)$ & - \\
\hline \multirow[t]{2}{*}{ Lymph node involvement } & Involved & $10(26.3)$ & - & $9(32.1)$ & - & $19(28.8)$ & - \\
\hline & Not involved & $28(73.7)$ & - & $19(67.9)$ & - & $47(71.2)$ & - \\
\hline \multirow[t]{4}{*}{ Tumor stage } & $\mathrm{T} 1$ & $4(10.5)$ & - & $2(7.1)$ & - & $6(9.1)$ & - \\
\hline & $\mathrm{T} 2$ & $6(15.8)$ & - & $3(10.7)$ & - & $9(13.6)$ & - \\
\hline & $\mathrm{T} 3$ & $18(47.4)$ & - & $18(64.3)$ & - & $36(54.5)$ & - \\
\hline & $\mathrm{T} 4$ & $10(26.3)$ & - & $5(17.9)$ & - & $15(22.7)$ & - \\
\hline \multirow[t]{2}{*}{ Mucinous } & Mucinous & $14(36.8)$ & - & $6(9.1)$ & - & $20(30.3)$ & - \\
\hline & Non-mucinous & $24(63.2)$ & - & $22(33.3)$ & - & $46(69.7)$ & - \\
\hline \multirow[t]{2}{*}{ Tumor grade } & High grade & $16(42.1)$ & - & $11(16.7)$ & - & $27(40.9)$ & - \\
\hline & Low grade & $22(57.9)$ & - & $17(25.8)$ & - & $39(59.1)$ & - \\
\hline Total & & $90(57.3)$ & & $67(42.7)$ & & $157(100)$ & \\
\hline
\end{tabular}

\section{HBoV PCR}

By a conventional PCR assay all samples were analyzed via specific primers for viral VP1 gene. Our results in CRC cases showed that there were $1.5 \%(1 / 66) \mathrm{HBoV}$ genome infection that compared to our non-CRC tissue it found in $1.1 \%$ (1/91) of their colonic tissue. Figure 1 showed the specific 579 bp PCR products of our two $\mathrm{HBoV}$ positive specimens.

The $\mathrm{HBoV}$ positive CRC case was a 63 years old female that tumor involved in sigmoid, tumor stage was
T3, tumor type was non-mucinous, well differentiated and low grade by the lymph node involvement, presentations. The $\mathrm{HBoV}$ positive from the control group was a 59 years old man by a normal tissue of colon.

Statistics showed there were not any significant results between presence of viral genome and different demographic variables but we showed the majority of included CRC cases were well differentiated, lack of lymph node involvement, non-mucinous, and low grade tumors.

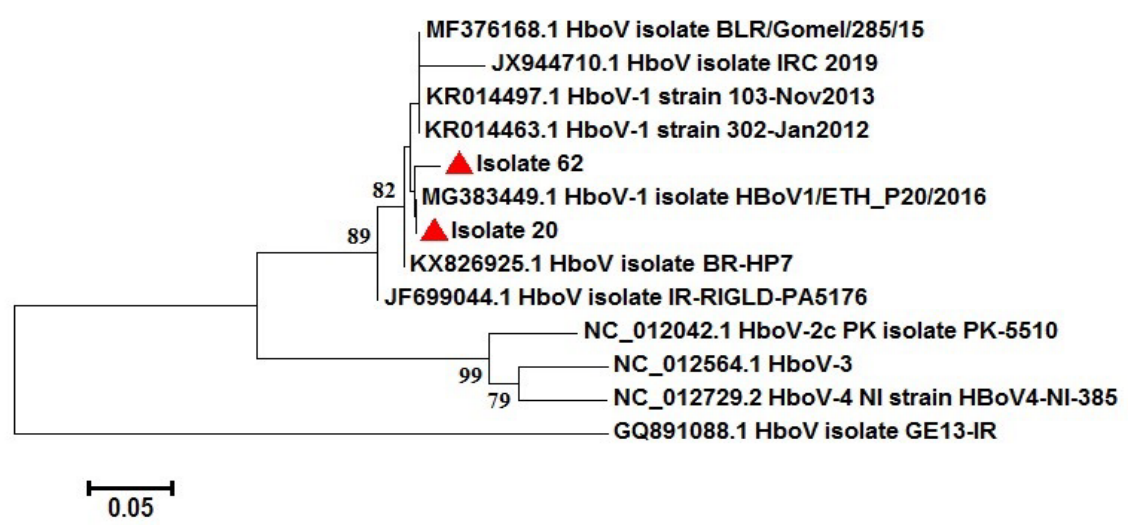

Figure 2. Phylogenetic Tree Draw by Neighbor-joining Algorithm for 579 bp Length of Open Reading Frame VP1 from our HBoV Strains. Bootstrap more than 70 obtained after 1000 replicates. The red triangles showed our isolates sequences. 


\section{Phylogenetic analysis}

A phylogenetic tree draw based on alignment of more similar and identical sequences to our trimmed consensus sequences. By the BLAST of our sequences we found that they were HBoV-1 genotype. The phylogenetic tree (Figure 2) showed our isolate sequences were closer to submitted sequences from Ethiopia (MG383449), and Italy (KR014497). HBoV-2, -3 and -4 genotypes reference sequences were obtained from GeneBank data base (https://www.ncbi.nlm.nih.gov/genbank).

\section{Discussion}

In the current study, we targeted 66 CRC cases and 91 non-CRC control groups for detection of $\mathrm{HBoV}$ genome infection in their colonic tissue by a conventional PCR assay. Results showed there were one (1.5\%) sample in cases and one $(1.1 \%)$ in control groups infected with HBoV genome. Phylogenetic analysis showed all of our positive isolates $(2 / 157)$ were $\mathrm{HBoV}-1$ genotype.

Recently, HBoV showed some relationships with respiratory and gastrointestinal diseases. $\mathrm{HBoV}$ potentials for establish a persistent infection by probably integration of viral genome in host chromosome, increase the concerns about its possible role in cancer production. Also, HBoV genome like other oncogenic viruses, found to establish a persistent infection in infected cells into a covalently closed circular DNA (cccDNA) form but it is not clear to be integrated into tumor cells or remains episomal (Kapoor et al., 2011; Lüsebrink et al., 2011). There are some reports that suggested closed circular DNA formation happened during $\mathrm{HBoV}$ DNA replication and also its episomal form could be exist in persistent infection that these findings showed the potential role of $\mathrm{HBoV}$ in cancer development (Berns, 1990; Hao et al., 2015; Kapoor et al., 2011). It is hypostatized that HBoV could be found in both lung and colorectal cancers while as a parvovirus it could replicate in dividing and proliferating cells (De Beeck and Caillet-Fauquet, 1997; Oleksiewicz and Alexandersen, 1997; Schildgen et al., 2013).

The HBoV-1 is the most prevalent genotype globally. Moreover, in the countries that enteric HBoV genotypes have been reported, these genotypes could be found in the solid tumors (Abdel-Moneim et al., 2016a). The present study results illustrates the presence of $\mathrm{HBoV}$ in solid tumor tissue as well as non-tumor tissue that indicates the potential of this parvovirus to remains persistent or latent.

$\mathrm{HBoV}-1$ has been mostly reported in respiratory airway, stool, plasma/serum and possibly lymphatic tissue samples that its persistent infection could recurrently occurred (Falcone et al., 2011; Schenk et al., 2007; Schildgen et al., 2013), especially in immunocompromised patients (Schenk et al., 2007). As a preliminary study in Iran, we found there were $1.3 \%(2 / 157) \mathrm{HBoV}$ genome in enteric tissue that could illustrate its possible role in further cancer development although we did not find significant result. It might due to the limited sample size or low prevalence of virus in our society.

In Iranian population there are some reports of $\mathrm{HBoV}$ infection in respiratory and stool samples but rare studies conducted by other samples (Nadji et al., 2010;
Naghipour et al., 2007). By the present study, we attempt to use enteric tissue samples as a preliminary study in Iran. Naghipour et al (Naghipour et al., 2007) in Iran first reported $\mathrm{HBoV}$ in $8 \%(21 / 261)$ of children with acute respiratory infections. Nadji et al (Nadji et al., 2010) in Iran used respiratory and stool samples from children with acute respiratory tract illnesses and gastroenteritis for detection of HBoV by NS-1 gene via PCR method. They reported $6.8 \%(9 / 133)$ of respiratory samples and $12.8 \%(6 / 47)$ of stool samples were $\mathrm{HBoV}$ positive. By our study results, we found that the prevalence of $\mathrm{HBoV}$ in cancerous and non-malignant tissue is less than other studies that could be due to our specific tissue samples compares with other respiratory or stool samples. Moreover, we targeted HBoV VP1 gene for analysis that is suitable for $\mathrm{HBoV}-1,-2,-3$ and -4 detection and differentiation by phylogenetic analysis. Mentioned studies used different parts of virus for detection and phylogenetic analysis such as NS-1 and VP1/2 gene junction that may impact on results.

Phylogenetic analysis of VP1/VP2 gene junction by Nadji et al., (2010) showed their isolates were HBoV-1, -2 and -3 . By the results, we identified our isolates were HBoV-1 genotypes that our limited positive strains could impact on our findings. Although, Abdel-Moneim et al., (2016b) reported there is just HBoV-1 genotype in tumor specimens and in Egypt without any evidence of other genotypes, our findings were similar to that report in contrast with other identified genotypes in Iranian non-tissue specimens evaluation.

Limitations of the present study was lack of other complimentary tests for $\mathrm{HBoV}$ detection such as western blot for viral protein expression or Real-time PCR methods although we utilized accurate and reliable direct sequencing method as a confirmatory test; limited sample size and using just archived FFPE blocks also should not be neglected. In further studies we recommend to use fresh samples as well as FFPE blocks, broader sample size especially in the case of CRC group and using other molecular and non-molecular based methods to get better comprehensive results.

In conclusion, in order to our analyzed specimens, the presence of HBoV genome in Iranian CRC patients as well as general population tissue is very low (almost 1\%) and the predominant genotype identified as $\mathrm{HBoV}-1$. By the current study, concerns about probable role of $\mathrm{HBoV}$ in CRC development in Iranian population is nearly far from proven. Further comprehensive studies need to get more understandings about $\mathrm{HBoV}$ role in carcinogenesis and related cellular damage for cancer development.

\section{Conflict of interest}

There are no competing interest by all authors.

\section{Acknowledgments}

We are acknowledge the kind assistance of Keyvan Lab. personnel. This project supports by Iran University of Medical sciences, Tehran, Iran by the grant number 9501-12-26671. 


\section{References}

Abdel-Moneim AS, Hosam A, Kamel MM, et al (2016) Screening of human bocavirus in surgically excised cancer specimens. Arch Virol, 161, 2095-2102.

Abdel-Moneim AS, Kamel MM, Hamed DH, et al (2016) A novel primer set for improved direct gene sequencing of human bocavirus genotype-1 from clinical samples. $J$ Virol Methods, 228, 108-13.

Afshar RM, Deldar Z, Mollaei HR, Arabzadeh SA, Iranpour M (2018). Evaluation of HPV DNA positivity in colorectal cancer patients in Kerman, Southeast Iran. Asian Pac J Cancer Prev, 19, 193.

Allander T, Tammi MT, Eriksson M, et al (2005). Cloning of a human parvovirus by molecular screening of respiratory tract samples. Proc Nebr Acad Sci, 102, 12891-6.

Basi A, Khaledi F, Karbalaie Niya MH, Rezvani H, Rakhshani N (2018). Epidermal growth factor receptor mutations in lung adenocarcinomas: A single center study from Iran. Asian Pac J Cancer Prev, 19, 111.

Berns KI (1990). Parvovirus replication. Microbiol Rev, 54, 316-29.

Bonvicini F, Manaresi E, Gentilomi GA, et al (2011). Evidence of human bocavirus viremia in healthy blood donors. Diagn Microbiol Infect Dis, 71, 460-2.

Brebion A, Vanlieferinghen P, Déchelotte P, et al (2014). Fatal subacute myocarditis associated with human bocavirus 2 in a 13-month-old child. J Clin Microbiol, 52, 1006-8.

Chen H, Chen XZ, Waterboer T, Castro FA, Brenner H (2015) Viral infections and colorectal cancer: a systematic review of epidemiological studies. Int J Cancer, 137, 12-24.

Coelho TR, Almeida L, Lazo PA (2010). JC virus in the pathogenesis of colorectal cancer, an etiological agent or another component in a multistep process?. Virol J, 7, 42 .

De Beeck AO, Caillet-Fauquet P (1997). Viruses and the cell cycle. Prog cell cycle res. Springer, pp 1-19.

Eftekhaar NS, Karbalaie Niya MH, Izadi F, Teaghinezhad-S S, Keyvani H (2017). Human papillomavirus (HPV) genotype distribution in patients with recurrent respiratory papillomatosis (RRP) in Iran. Asian Pac J Cancer Prev, 18, 1973.

Falcone V, Ridder GJ, Panning M, et al (2011). Human bocavirus DNA in paranasal sinus mucosa. Emerg Infect Dis, 17, 1564.

Hao Y, Gao J, Zhang X, et al (2015). Seroepidemiology of human bocaviruses 1 and 2 in China. PLoS One, 10, e0122751.

Kapoor A, Slikas E, Simmonds P, et al (2009). A newly identified bocavirus species in human stool. J Infect Dis, 199, 196-200.

Kapoor A, Simmonds P, Slikas E, et al (2010). Human bocaviruses are highly diverse, dispersed, recombination prone, and prevalent in enteric infections. J Infect Dis, 201, 1633-43.

Kapoor A, Hornig M, Asokan A, et al (2011). Bocavirus episome in infected human tissue contains non-identical termini. PLoS One, 6, e21362.

Karbalaie Niya MH, Basi A, Koochak A, et al (2016). Sensitive high-resolution melting analysis for screening of KRAS and BRAF mutations in Iranian human metastatic colorectal cancers. Asian Pac J Cancer Prev, 17, 5147.

Karbalaie Niya MH, Safarnezhad Tameshkel F, Panahi M, et al (2017). Human papillomavirus investigation in head and neck squamous cell carcinoma: Initial report from the low risk HPV types associations. Asian Pac J Cancer Prev, 18, 2573.

Karbalaie Niya MH, Salman-Tabar S, Bokharaei-Salim F, Behmanesh M, Keyvani H (2017). Prevalence of resistant associated variants (RAVs) in the naïve HCV patient candidate for direct acting antiviral (DAA) therapy. Microb
HBoV Molecular Epidemiology in Colorectal Specimens

Pathogen, 105, 166-70.

Karbalaie Niya MH, Keyvani H, Tameshkel FS, et al (2018). Human papillomavirus type 16 integration analysis by real-time PCR assay in associated cancers. Translational Oncol, 11, 593-8.

Keyvani H, Karbalaie Niya MH, Esghaei M, Bokharaei-Salim F, Monavari SHR (2017). Presence of human herpesvirus 8 (HHV-8) DNA sequences in patients with lymphoproliferative diseases and chronic blood disorders. Microb Pathogen, 111, 431-4.

koochak A, Rakhshani N, Karbalaie Niya MH, et al (2016). Mutation analysis of KRAS and BRAF genes in metastatic colorectal cancer: a first large scale study from Iran. Asian Pac J Cancer Prev, 17, 603-8.

Koskenvuo M, Möttönen M, Waris M, et al (2008). Human bocavirus in children with acute lymphoblastic leukemia. Eur J Pediatr, 167, 1011-5.

Li Y, Dong Y, Jiang J, et al (2012). High prevelance of human parvovirus infection in patients with malignant tumors. Oncol lett, 3, 635-40.

Lüsebrink J, Schildgen V, Tillmann RL, et al (2011). Detection of head-to-tail DNA sequences of human bocavirus in clinical samples. PLoS One, 6, e19457.

Mitui MT, Shahnawaz Bin Tabib S, Matsumoto T, et al (2012). Detection of human bocavirus in the cerebrospinal fluid of children with encephalitis. Clin Infect Dis, 54, 964-7.

Mortazavi HS, Monavari SH, Molaee H, Keyvani H, Pirkooh AA (2015). Human bocavirus in hospitalized Iranian adults with respiratory tract infections during January-June 2014. J Pure Appl Microbiol, 9, 483-8.

Munoz N (2000). Human papillomavirus and cancer: the epidemiological evidence. J Clinl Virol, 19, 1-5.

Nadji SA, Poos-Ashkan L, Khalilzadeh S, et al (2010). Phylogenetic analysis of human bocavirus isolated from children with acute respiratory illnesses and gastroenteritis in Iran. Scand J Infect Dis, 42, 598-603.

Naghipour M, Cuevas LE, Bakhshinejad T, Dove W, Hart CA (2007). Human bocavirus in Iranian children with acute respiratory infections. J Med Virol, 79, 539-43.

Oleksiewicz MB, Alexandersen S (1997). S-phase-dependent cell cycle disturbances caused by Aleutian mink disease parvovirus. $J$ Virol, 71, 1386-96.

Romani S, Mohebbi SR, Khanyaghma M, et al (2013). Detection of human Bocavirus 1, 2 and 3 from patients with acute gastroenteritis. Gastroenterol Hepatol Bed Bench, 6, S77.

Schenk T, Strahm B, Kontny U, et al (2007). Disseminated bocavirus infection after stem cell transplant. Emerg Infect Dis, 13, 1425.

Schildgen V, Malecki M, Tillmann R-L, Brockmann M, Schildgen O (2013). The human bocavirus is associated with some lung and colorectal cancers and persists in solid tumors. PLoS One, 8, e68020.

Shen J, Zhu Q, Zeng M, Yu H (2013). Detection and genome analysis of human bocavirus 1-4 from hospitalized children with acute lower respiratory tract infection and symptoms of wheezing in Shanghai. Int J Mol Med, 32, 1415-20.

Siegel RL, Miller KD, Fedewa SA, et al (2017). Colorectal cancer statistics, 2017. CA Cancer J Clin, 67, 177-93.

This work is licensed under a Creative Commons AttributionNon Commercial 4.0 International License. 